\title{
UNA ATRIBUCIÓN A PIETRO DI MARTINO VEESE: EL ESCUDO DE ARMAS DE CARLOS II ENTRE ÁNGELES TENANTES DE LA IGLESIA DE LAS CALATRAVAS DE MADRID Y LA INFLUENCIA DE BERNINI EN LA DECORACIÓN ESPAÑOLA DEL BARROCO.
}

Sobre la puerta del brazo del crucero del lado de la epístola de la iglesia de la Concepción Real de Calatrava de Madrid, vulgo Calatravas, que da paso a la sacristía y a la sala capitular del templo, existe un elegante altorrelieve que representa un Escudo de armas del rey Carlos II entre dos ángeles tenantes, dispuesto como remate a todo los ancho del dintel (Fig. 1) ${ }^{1}$. Está pintado con un color claro de tonalidad gris verdosa y debe estar realizado en estuco o en barro a juzgar por los planos excavados, los agujeros y las imperfecciones de ciertas partes del mismo, por lo general de carácter secundario y menos visible, como los cuerpos de los leones o las esferas que sujetan con sus garras. A su perfil mixtilíneo se le sobrepone una cornisa como apoyo del altorrelieve, que se estructura a partir de un pedestal que arranca en volutas horizontales y sirve de apoyo a un escudo de perfiles ondulantes rematado con la correspondiente corona. Tormo identificó el escudo con el correspondiente al rey Carlos $\mathrm{II}^{2}$. A diferencia del perteneciente a Felipe IV, carece del cuartel correspondiente al reino de Portugal, perdido de facto para la Corona en la década de 1640 y de iure durante la regencia de la reina Mariana de Austria. Por detrás de las armas afloran los brazos de una cruz de Calatrava y el collar del Toisón de Oro que cuelga por el frente del pedestal. El conjunto se halla guarnecido por festones florales y está flanqueado por dos figuras tenantes de ángeles mancebos con alas y drapeados dinámicos (Figs. 2 y 3 ). Dos leones, que tienen entre sus garras sendos globos terráqueos (Fig. 4), aparecen directamente tendidos sobre la cornisa, cerrando de este modo un esquema en triángulo equilátero dentro del cual queda inscrito todo el conjunto.

La colocación de las armas reales en un lugar tan relevante, así como en las pechinas de la cúpula, indica con claridad la preeminencia del rey en el escalafón de las órdenes militares y el patronato real que se extendía sobre ellas.

La solución de la cornisa por encima de las molduras de la puerta es semejante a la que muestran los balcones del primer piso del claustro del Colegio Imperial de Madrid, obra de Melchor de Bueras hacia 1679, y la riqueza ornamental del relieve coincide con la de la reconstrucción de la Casa de la Panadería de la Plaza Mayor de Madrid, tras el incendio de 1672, en la que intervino Tomás Román ${ }^{3}$.

Por su fuerte estilo italiano se trata de una obra excepcional y de un vestigio único en la escultura madrileña del último tercio del siglo xVII. No obstante, en raras ocasiones ha sido mencionado, a pesar de que por su calidad y su condición de obra integrada en la arquitectura merecen algún comentario. La cronología y el estilo de la obra son los dos elementos básicos a analizar a fin de precisar una posible autoría o un acercamiento a otras obras similares.

En cuanto a la cronología, el elemento fundamental para la datación de la obra nos lo proporciona su encuadre en la arquitectura y la identificación del escudo de armas. En cuanto a la primera, el contrato para la fábrica de la iglesia fue suscrito entre la comunidad de la Concepción Real de Calatrava y los maestros de obras Gregorio Garrote e Isidro Martínez el 30 de agosto de 1670, quienes siguiendo los planos y condiciones de fray Lorenzo de San Nicolás la terminaron antes del 4 de enero de 1678, día en el que fray Lorenzo fue nombrado para tasar-

\footnotetext{
1 Virginia Tovar Martín, Arquitectos madrileños de la segunda mitad del siglo xVII. Madrid, 1975, pp. 92-99. Aunque se analiza la decoración escultórica del edificio, no se menciona este adorno completamente integrado en la arquitectura.

${ }^{2}$ Elías Tormo, Las iglesias de Madrid. Reedición de los dos fascículos publicados en 1927. Prólogo del marqués de Lozoya. Notas de María Elena Gómez Moreno. Madrid, Instituto de España, 1979, p. 151.

${ }^{3}$ Tovar Martín, op. cit., 1975, pp. 303-304 y 371.
} 
la ${ }^{4}$. No se cita esta obra en ninguno de las setenta y un apartados de que consta el documento de tasación ${ }^{5}$, por lo que habrá que pensar que el Escudo con las armas de Carlos II entre ángeles tenantes sea posterior a esta fecha y que la decoración de la iglesia no estaba acabada por completo. De hecho, en 1684 Juan de Pineda y Juan Sánchez Prieto volvían a medir y tasar el edificio «incluyéndose ya en esta inspección los remates de la sacristía y labores de adorno complementarias» ${ }^{6}$. No es descartable que entre estas labores de adorno complementarias se encontrara el altorrelieve, que en principio parece probable que fuera realizado en una fecha comprendida entre 1678-1684 o poco después. A este efecto el gran lienzo de El venerable Diego Velázquez, fundador de la Orden de Calatrava, que ocupó el antiguo retablo mayor, es obra de Ignacio Ruiz de la Iglesia fechada en 1688, aunque el pintor comenzó a cobrar el trabajo desde diciembre de $1686^{7}$.

El estilo que muestran las figuras de este relieve es claramente italiano y se relaciona con los modelos creados a partir de 1640 en Roma por Gian Lorenzo Bernini, junto con sus discípulos, colaboradores y seguidores. En las figuras de los dos ángeles destacan los paños que ciñen sus cuerpos desnudos. Las telas revolotean en plegados transversales, diagonales y acaracolados, con hondos surcos de profundas sombras y de aristas cortantes. Los rostros están cargados de expresividad. El plumaje de las alas tiene calidades táctiles. En otros detalles como son las flores de los festones, las cabelleras de los ángeles y las melenas de los leones, el escultor trabaja en profundidad, buscando efectos de trépano.

Uno de los introductores de las novedades barrocas romanas en la corte de Madrid fue el escultor italiano Juan Bautista Morelli, presente en España desde 1659 hasta su muerte en agosto de 1669 , a quien Diego Velázquez había conocido en Roma durante su segundo viaje a Italia ${ }^{8}$. Se conocen muy pocas obras seguras de su mano. No se han conservado las obras citadas por Palomino, ni otras documentadas, aunque bien descritas, como es el caso de los frisos de San Antonio de los Alemanes (1668) ${ }^{9}$. De modo unánime le han sido atribuidos los estucos recientemente descubiertos del despacho de Felipe IV en el palacio de Aranjuez (1668-1669) ${ }^{10}$, genéricamente citados por Palomino entre las obras hechas para el rey y no concluidas, realizados en un lugar en el que el escultor residió. El desconocimiento de otros estucadores contemporáneos que pudieran desplegar un estilo semejante en ese momento refuerza la atribución.

El fallecimiento de Morelli en Madrid en agosto de 1669 le excluye como autor del Escudo de armas de Carlos II entre angeles tenantes. Por otro lado, su comparación formal con los

\footnotetext{
4 Ibidem, p. 94.

5 Virginia Tovar Martín, Arquitectura madrileña del s. XVII. (Datos para su estudio). Madrid, 1983, pp. 571-577, documento 75 .

${ }^{6}$ Ibidem, p. 318. La autora no da la referencia del documento para poder comprobar los términos de los que deduce una afirmación semejante.

7 Teresa Zapata Fernández de la Hoz, «Nuevas obras sobre la vida y la obra de Francisco Ignacio Ruiz de la Iglesia», en Archivo Español de Arte, LIV, n. ${ }^{\circ} 216,1981$, pp. 429-430.

${ }^{8}$ Sobre Juan Bautista Morelli en España, véase la mención de Antonio Palomino de Castro y Velasco. El Museo pictórico y la Escala óptica. Madrid, edic. Aguilar, 1947, pp. 927-928. Mercedes Agulló y Alfonso E. Pérez Sánchez, «Juan Bautista Morelli», en Archivo Español de Arte, XLIX, n. ${ }^{\circ}$ 194, 1976, pp. 109-120. Ismael Gutiérrez Pastor - José Luis Arranz Otero. «La decoración de San Antonio de los Portugueses (1660-1702)», en Anuario del Departamento de Historia y Teoría del Arte (U.A.M.), vol. XI, 1999, pp. 211-249. Ismael Gutiérrez Pastor, «Juan Bautista Morelli en San Antonio de los Portugueses», en Anuario del Departamento de Historia y Teoría del Arte (U.A.M.), vol. XIII, 111-117. José Luis Sancho, «Ianus Rex. "Otra cara" de Carlos II y del Palacio Real de Aranjuez. Morelli y Giordano en el despacho antiguo del Rey», en Reales Sitios, n. ${ }^{\circ}$ 154, 2002, pp. 34-45. Mercedes Agulló y Cobo, «Juan Bautista Morelli y sus hijos en la Corte española», en Boletín del Museo Nacional de Escultura, 6 (Valladolid, 2002), pp. 26-35.

${ }_{9}^{9}$ Gutiérrez Pastor, op. cit., 2001, pp. 111-117. Gutiérrez Pastor - Arranz Otero, op. cit., 1999, pp. 211-249.

${ }^{10}$ Sancho, op. cit., 2002, pp. 34-45. Javier Jordán de Urries y de la Colina, «Luca Giordano en el Palacio Real de Aranjuez», en Reales Sitios n. ${ }^{\circ}$ 159, 2004, pp. 60-73, en donde se reconstruye la decoración total del Despacho del Rey. Sobre otros trabajos en Aranjuez, véase Gloria Martínez Leiva, «El Salón o galería de paisajes del palacio Real de Aranjuez bajo el reinado de Felipe IV», en Reales Sitios, n. ${ }^{\circ} 159,2004$, pp. 26-46.
}

$A E A$, LXXVIII, 2005, 312, pp. 413 a 438 


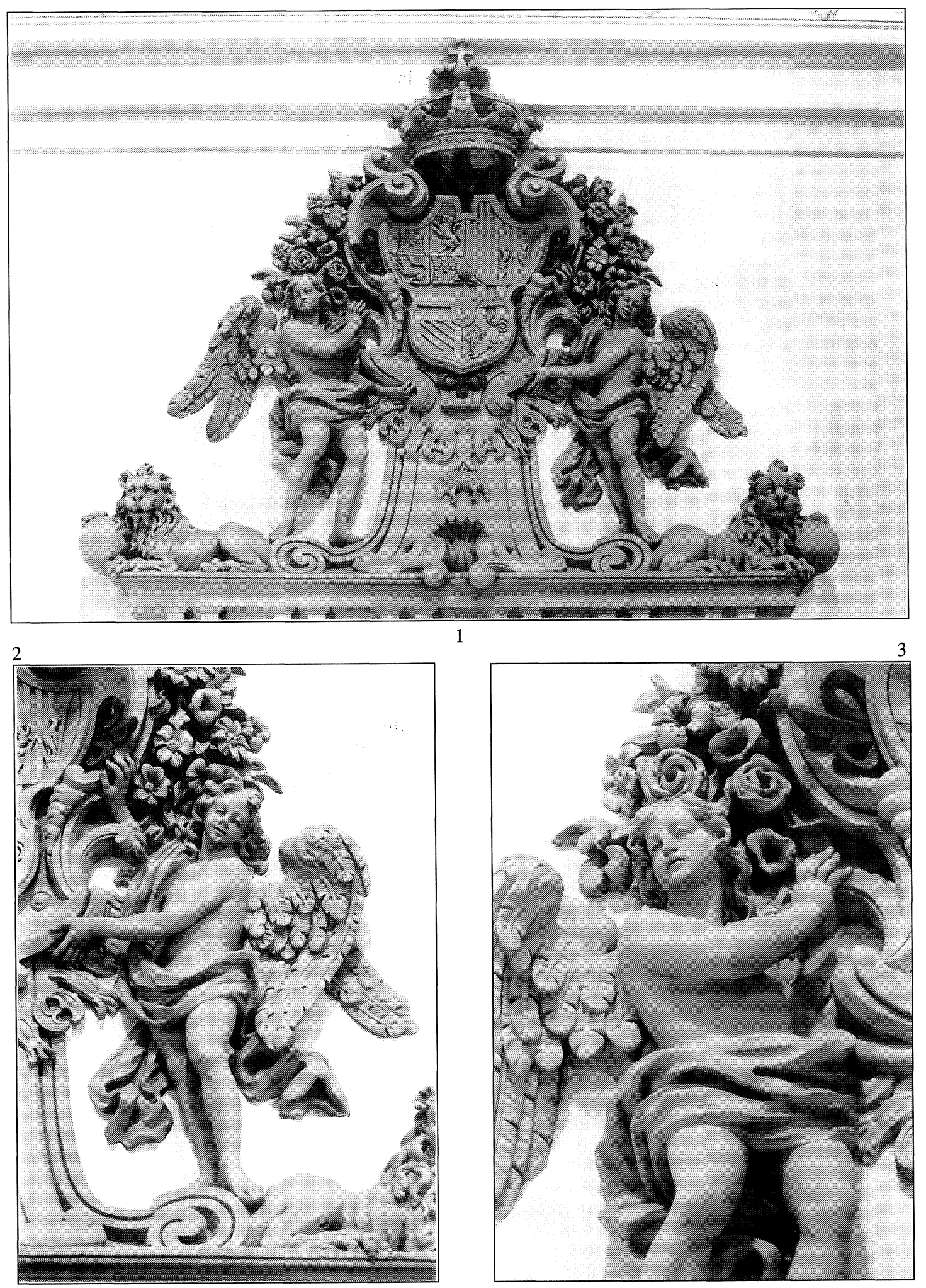

Fig. 1. Escudo de armas de Carlos II entre ángeles tenantes. Madrid, iglesia de las Calatravas. Hacia 1679-1684 Fig. 2. Detalle del ángel del lado derecho.

Fig. 3. Detalle de un ángel del lado izquierdo. 
estucos del despacho de Felipe IV revela estilos muy diferentes. Las figuras del despacho del palacio de Aranjuez muestran formas largas y un modelado en bajorrelieve, con insistencia en el trabajo de la anatomía dentro de esa planitud de las formas. La tendencia hacia la serenidad del clasicismo barroco domina en las figuras de la mitología clásica, en las alegorías de las virtudes cristianas, en las esfinges junto a los escudos de los ángulos y en los ángeles niños. Por el contrario, los angeles tenantes del escudo de armas de las Calatravas están modelados en altorrelieve con algunas partes en bulto redondo, como las cabezas, los brazos y las piernas de los ángeles. Son figuras más dinámicas en sus actitudes y más expresivas en sus rostros, con telas que ciñen sus cuerpos de plegados excavados y aristas cortantes, al mejor estilo romano. Entre las figuras de una y otra obra es apreciable la misma diferencia estilística que en las obras romanas de Algardi, con quien colaboró Morelli, y de Bernini. Tampoco sabemos que Morelli llegase a formar un taller y, si en cualquier caso lo hizo y formć a escultores españoles en el estilo barroco italiano, su estilo no se manifiesta en el Escudo de armas de las Calatravas. Sus hijos siguieron la profesión de pintores bajo la tutela de Andrés Smith ${ }^{11}$.

Otro fue Giuliano Finelli, habitualmente considerado orfebre, pero que en la documentación de la catedral de Toledo aparece también como escultor en plata y broncista, que falleció el 10 de noviembre de $1678{ }^{12}$. Una de sus obras más conocida fue el trono de plata de la Virgen del Sagrario, obra de larga gestación y ejecución, en la que participaron los mejores ensambladores y escultores de Madrid desde 1646. En 1671 realizó la escultura en plata para las fiestas de canonización de San Fernando y otra que estaba en el relicario de la catedral ${ }^{13}$.

Ante una obra de esta naturaleza, que parece que tuvo que ser realizada in situ, salvo que fuera hecha en Roma y trasladada posteriormente a Madrid, surge el interrogante acerca de su autor. La cronología nos lleva a fechas comprendidas entre 1678-1684 y el estilo a un escultor de profunda formación italiana, conocedor de lo que unos quince o veinte años antes se venía haciendo en Roma. Lo mismo importa que fuera un escultor de origen italiano, que un español formado en la ciudad papal. Falta documentación y precisión sobre la obra que nos ocupa.

Los escultores italianos y los españoles formados en Roma activos en Madrid en esos años no fueron numerosos. En la documentación de la catedral de Toledo consta que el cardenal don Luis Manuel Fernández de Portocarrero nombró el 27 de junio de 1679 a «Pedro de Martino Veese» escultor de la Santa Iglesia de Toledo. En 1682 el mismo cardenal mandó que no se le pagase su salario ${ }^{14}$. Debe de tratarse del «Pietro Mentinoves» (Mentino -Ves) que documenta Zapata el mismo año interviniendo en las decoraciones escultóricas para la entrada de la reina María Luisa de Orleans en Madrid, realizando una estatua de la Fortuna destinada a coronar con la portada del Buen Retiro y también la mitad de las veinticuatro estatuas de ríos y fuentes con las que se decoraron las galerías del patio del Alcázar Real, como resultado del traspaso de contrato que le hicieron Francisco de Viña y Lucas Villamé ${ }^{15}$. En los documentos se le

\footnotetext{
$"$ Agulló y Cobo, op. cit., 2002. Sobre la identificación de este Pedro de Obregón con el pintor de igual nombre y sus dificultades, vease p. 34 y notas 19 y 20, en donde se tiene en cuenta lo escrito por Alfonso E. Pérez Sánchez, Pintura barroca en España, 1600-1750. Madrid, 1992, p. 92, pero no a los grabadores de apellido Obregón: Pedro (1597-1659) y sus hijos Diego (activo entre 1669-1693) y Marcos (†1720), además de otro Pedro, de quien se duda respecto al parentesco, sugiriendo que haya podido ser otro hijo. Véase Elena Páez Ríos, Repertorio de grabados españoles en la Biblioteca Nacional, tomo II, H-Q. Madrid, 1982, pp. 305-308.

12 Pérez Sedano, op. cit., pp. 108, 104-105, 107, 129 у 135.

13 Ibidem, pp. 104-105 y 134-135, 106-107 y 129.

${ }^{14}$ Francisco Pérez Sedano, Datos documentales inéditos para la Historia del Arte Español. I. Notas del Archivo de la Catedral de Toledo, redactadas sistemáticamente en el siglo xvII por el canónigo-archivero Don Francisco Pérez Sedano. Madrid, 1914, p. 108.

${ }_{15}$ Teresa Zapata, La entrada en la Corte de María Luisa de Orleans. Arte y fiesta en la Corte de Carlos II. Madrid, Fundación de Apoyo a la Historia del Arte Hispánico, 2000, pp. 192 y 195, nota 530. Viñas era de origen flamenco y junto con su compatriota Blondei trabajaron en los estucos del paso de la parroquia de San Andrés a la capilla de San Isidro es uno de los estuquistas.
}

$A E A$, LXXVIII, 2005, 312, pp. 413 a 438 


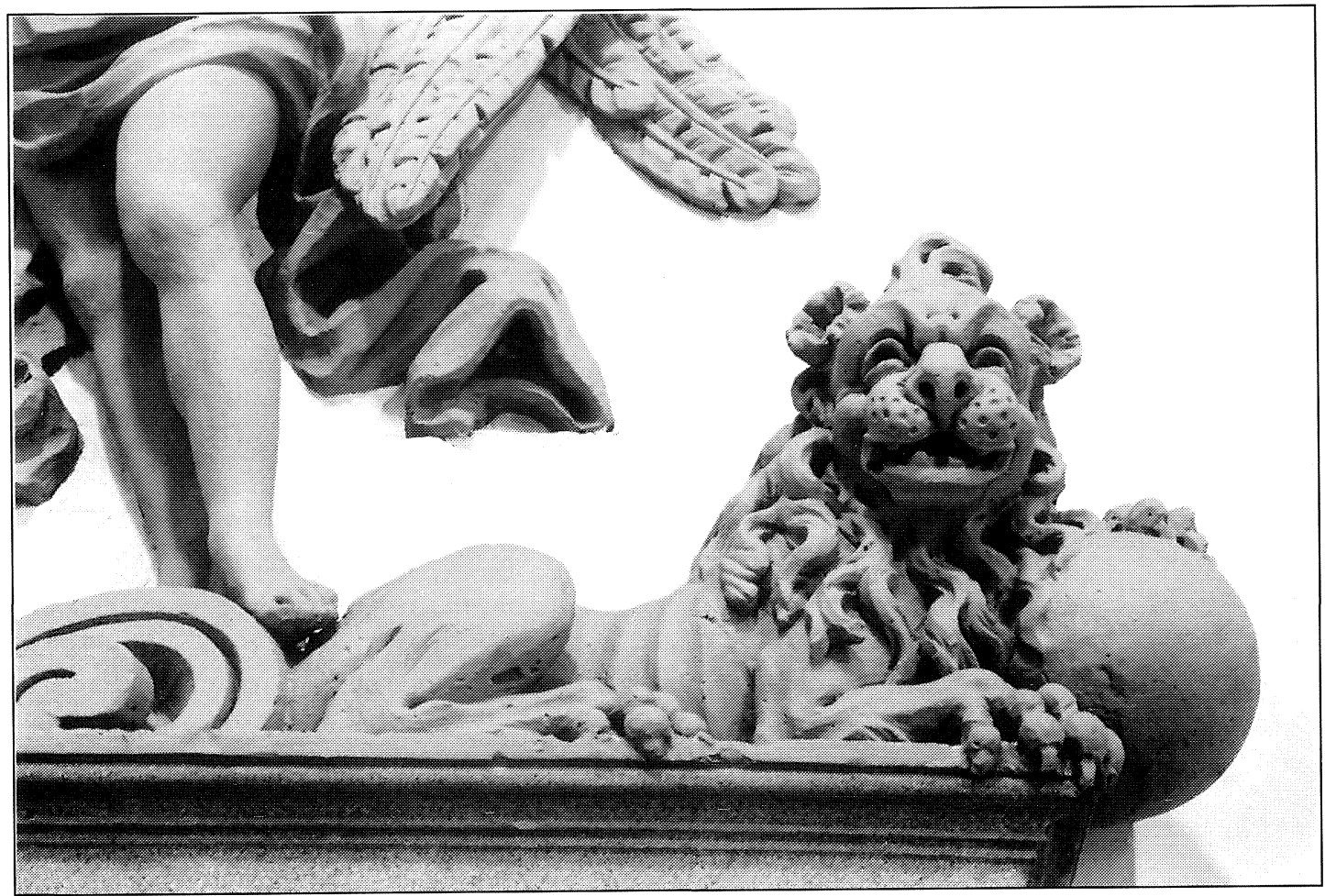

4

5
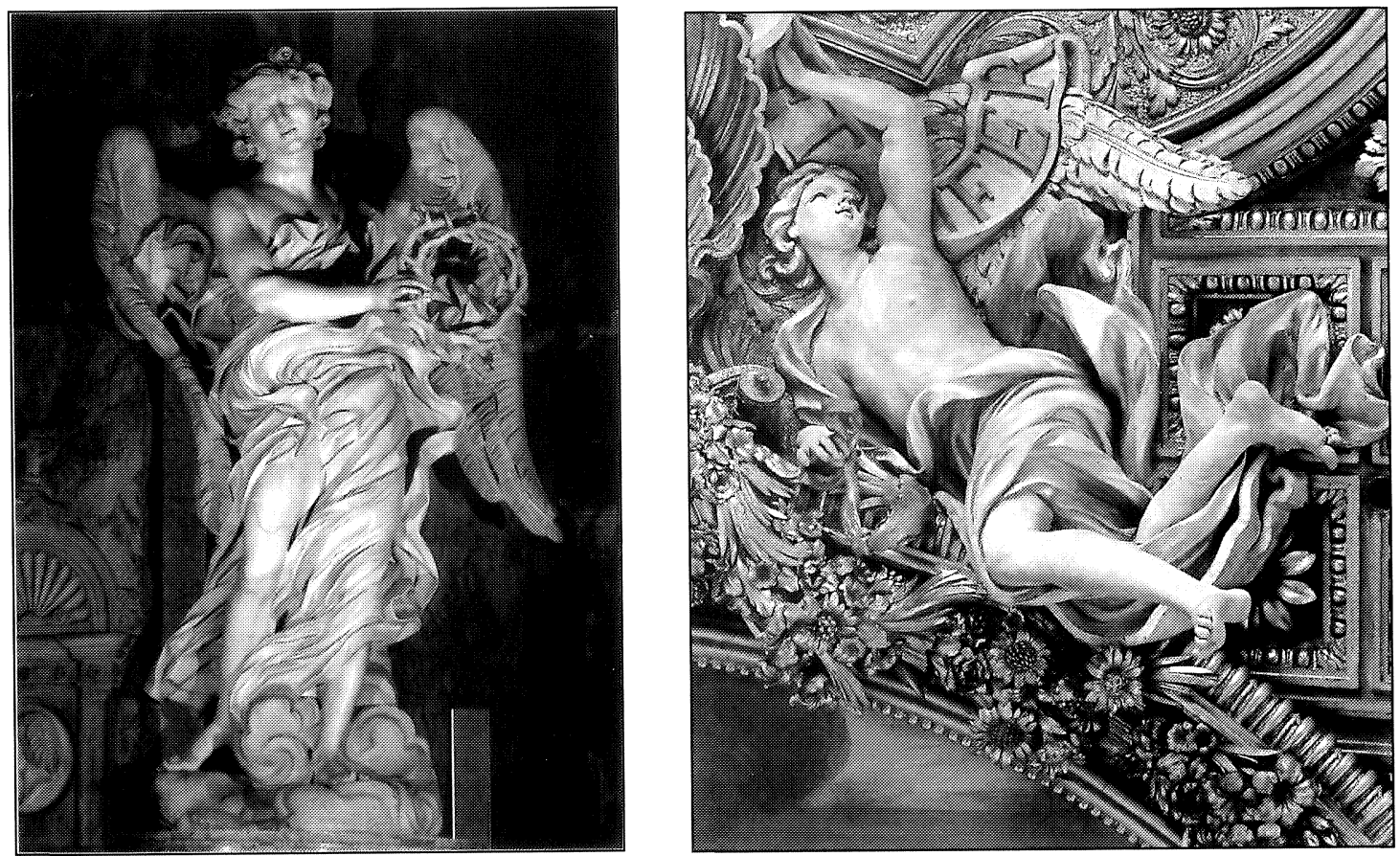

Fig. 4. Detalle de un león.

Fig. 5. Gian Lorenzo Bernini. Ángel con corona de espinas. Roma, S. Andrea delle Fratte.1668-1669.

Fig. 6. Antonio Raggi. Ángel. Bóveda de la iglesia del Gesù. Roma. 1677.

AEA, LXXVIII, 2005, 312, pp. 413 a 438 
menciona como «escultor de Su Eminencia el Sr. Cardenal», que Zapata, sin tener en cuenta los documentos de la catedral de Toledo, supone acertadamente que sea el influyente cardenal Portocarrero (1635-1709) ${ }^{16}$, quien antes había sido vicario de Toledo en ausencia del arzobispo cardenal don Pascual de Aragón, cardenal protector de los españoles en Roma (1669), virrey de Sicilia (1676-1677) y finalmente arzobispo de Toledo (preconizado en diciembre de 1677), llamado a jugar un papel decisivo en la sucesión española a la muerte de Carlos II. A su regreso a España (1678) se hizo acompañar por un nutrido séquito de músicos y artistas italianos, entre los cuales pudo haber estado el mencionado escultor ${ }^{17}$. La obra de Pietro di Martino Veese en la puerta del Buen Retiro fue tasada el 17 de septiembre de 1680 por José de Mora, escultor del rey, y Francisco Rizi, pintor del rey. A finales de diciembre de 1679 urgía terminar la estatua y ante el retraso en el trabajo se le mandó al escultor que hiciera la estatua de la Fortuna de modo provisional en yeso para colocarla sobre la puerta del Buen Retiro y dejarla preparada para la celebración de la entrada, en tanto terminaba la definitiva en piedra de Tamajón ${ }^{18}$, la cual no llegó a ocupar su lugar hasta diez años más tarde con motivo de la entrada de la reina Mariana de Neoburgo en $1689^{19}$. El 30 de marzo de 1680 Juan Carreño de Miranda tasaba su trabajo en la plaza del Alcázar Real ${ }^{20}$.

Ninguna de estas decoraciones, efímeras en su mayor parte, han sido identificadas. Por ello, resulta bastante arriesgado plantear la atribución del Escudo de armas de Carlos II entre dos ángeles tenantes a Pietro di Martino Veese y tal atribución sólo puede tomarse como provisional a la espera de que conozcamos más datos o algunas obras seguras de este escultor, que tiene a su favor el origen y la formación italianas. De acuerdo con el estatuto de los oficiales de la catedral de Toledo, cuando un artista dejaba de percibir su salario, tal y como ocurrió en el caso de Pietro di Martino Veese en 1682, las causas solían radicar por lo general en el hecho de que el artista dejaba de residir en la ciudad ${ }^{21}$. Sin embargo no podemos afirmar si el escultor se trasladó a otra ciudad, como por ejemplo Madrid, donde residía la Corte y donde las ocasiones de trabajo podían ser mayores, o si volvió a Italia. En el segundo caso, la cronología del relieve se podría fijar entre 1679-1682, quedando englobada entre los trabajos que Juan de Pineda y Juan Sánchez Prieto pedían tasar en 1684.

Lo que muestran los ángeles y los festones florales del altorrelieve de las Calatravas es un profundo conocimiento de la obra de Gian Lorenzo Bernini y de sus colaboradores y discípulos, correspondiente a las décadas de 1660 y 1670. Los dos ángeles tenantes evocan en primer lugar a los que flanquean la cátedra de San Pedro, proyectados hacia 1658-60, pero fundidos en 1665 e instalados en todo el conjunto antes de su inauguración oficial en

Pietro di Martino Veese no fue el único toledano que trabajó en la escultura y pintura de la entrada de María Luisa de Orleans. También lo hicieron los escultores Juan Pablo de Estrada e Ignacio Alonso, y el pintor Simón Vicente ( $C f r$. Paula Revenga Domínguez, Pintura y pintores toledanos de la segunda mitad del siglo XVII. Madrid, 2001, p. 354).

16 J. Gómez-Menor Fuentes, «Primera nota biográfica sobre el cardenal don Luis Manuel Fernández-Portocarrero, Arzobispo de Toledo (1635-1709)», en Anales de Arte Toledano, n1 5, 1971, pp. 105-116.

17 Zapata, op. cit., 2000, pp. 56, 76-77 y 249, documentos 1 g, 1 h; p. 250, documento 2 g, 2 i; y pp. 313-314, documentos $41 \mathrm{j}, 41 \mathrm{p}$.

18 Ibidem, pp, 249-250, documentos $1 \mathrm{~g} \mathrm{y} 2 \mathrm{~g}, \mathrm{~h}, \mathrm{i}, \mathrm{y}$ j.

${ }_{19}$ Ibidem, p. 78. Según la autora la iconografía de esta Fortuna la representaba alada, razón por la cual la puerta fue conocida como Puerta del Ángel.

${ }^{20}$ Ibidem, p. 56 , p. 250 , documento 2 i, p. 314 , documento 41 p.

${ }^{21}$ Sobre estas cuestiones de las maestrías y oficialías de las artes en la catedral de Toledo, véase la obra de Paula Revenga Domínguez, Pintura y sociedad en el Toledo Barroco, Toledo, 2002, pp. 263 y ss. Aunque el estudio se refiere al caso de los pintores, con algún ejemplo de arquitectos y maestros de obras, el régimen era semejante en el de los escultores. Las excepciones de residencia que se produjeron en la segunda mitad del siglo xvir: Francisco Rizi, José Jiménez Donoso... lo fueron en su condición de pintores. Donoso renunció al salario de maestro mayor de obras y de este modo residió en Madrid (Ibidem, p. 269-270). Según comunicación personal de la Dra. Revenga Domínguez la falta de residencia es lo que hizo que Pedro de Mena (nombrado escultor de la catedral el 7 de mayo de 1663) renunciara a su salario.

$A E A$, LXXVIII, 2005, 312, pp. 413 a 438 
$1666^{22}$. También a los diseñados para el Ponte de Sant'Angelo a partir de 1667, que con todo su complejo proceso estaban colocados en su emplazamiento en 1671 (Fig. 5) ${ }^{23}$. En ambos casos la participación en la ejecución de colaboradores de Bernini como Ercole Ferrata, Giorgetti, Girolamo Lucentti, Domenico Guidi, Lazaro Morelli, Antonio Raggi, Paolo Naldini y Fancelli está perfectamente documentada ${ }^{24}$. Los festones de flores son igualmente berninianos y sus antecedentes más claros están en los que adornan las cúpulas de Santo Tomás de Castel Gandolfo (1658-1661) y S. Andrea al Quirinale (1658-1670) de Roma, con estucos en su mayor parte del Antonio Raggi, estos realizados entre 1662-1665. Los estucos de S. Maria de Ariccia (1662-1664) fueron ejecutados por Paolo Naldini en $1664{ }^{25}$. La estética de la escultura de Bernini se extiende por muchos ejemplos de la arquitectura barroca de Roma, pero alcanza una modélica conjunción ilusionista en la bóveda de la iglesia del Gesù mediante la combinación de estucos de Antonio Raggi (Fig. 6) y de pintura de G. B. Gaulli, il Baciccia, todo ello realizado entre 1676-1679 ${ }^{26}$. Es quizá la obra con la que presenta más similitudes el $E s$ cudo de las armas de Carlos II entre dos ángeles tenantes de las Calatravas de Madrid. Sin embargo, en el caso de aceptar a Di Martino como autor del altorrelieve, el escultor no pudo conocer la obra del Gesù concluida, pues para entonces ya se encontraba en Madrid, siendo su terminación coetánea de las decoraciones para la entrada de la reina María Luisa de Orleans en Madrid. En cualquier caso la obra de las Calatravas, aun considerándola de un artista desconocido, representaría un ejemplo temprano y concreto de la influencia en Madrid de las decoraciones de Bernini y los suyos, con Raggi a la cabeza ${ }^{27}$.

No hemos encontrado más datos sobre este escultor, del que hasta su nombre resulta un enigma.

Entre los españoles que se formaron en Italia se encuentra el zaragozano Juan de Revenga (Zaragoza, c.1610-Madrid, 1684), que se especializó en la escultura en cera y se estableció en Madrid como un caballero, trabajando «por diversión sin llevar dinero por sus obras... proponiendose no trabajar obra alguna pública», aunque acosado por las críticas tuvo que hacer algunas para demostrar su valía ${ }^{28}$. Aunque por cronología y formación pudiera haber sido un buen candidato a la autoría del Escudo de armas, el juicio de Ceán Bermúdez lo condiciona mucho, aunque no lo descarta de modo definitivo. Sin que conste que hubiera estado en Italia, el estilo de Pedro Alonso de los Ríos (Valladolid, 1641-Madrid, 1702) representa un avance dentro de la escultura madrileña de la segunda mitad del siglo XVII. En sus obras se percibe la influencia dinámica y los pliegues en arista de origen romano, como es visible en los relieves de la Oración en el huerto y de la Ascensión de la catedral de Burgos, realizados entre 1681 y 1683.

${ }^{22}$ Rudolf Wittkower. Gian Lorenzo Bernini, El escultor del barroco romano. Edición revisada por Howard Hibbard, Thomas Martin y Margot Wittkower. Madrid, Alianza Editorial, 1990, pp.273-276.

${ }^{23}$ Ibidem, pp. 287-292.

${ }^{24}$ Sobre la organización del taller de Bernini y su colaboración ocasional con otros maestros, véase Wittkower, op. cit., 1990, pp. 54-62.

${ }^{25}$ Wittkower, op. cit., 1990, pp. 276-279.

${ }^{26}$ Véase el capítulo de Gauvin Alexander Bailey, «La contribución de los Jesuitas a la pintura italiana y su influjo en Europa, 1540-1773», en Giovanni Sale, s.i. (Ed.). Ignacio y el arte de los Jesuitas.Bilbao, Ediciones Mensajero, 2003, pp.122-168

${ }^{27}$ Por si se descubriera que la cronología del relieve es más avanzada que la que aquí se propone, vale la pena recordar que en Valencia trabajaron algunos estuquistas y escultores italianos estrechamente relacionados con Madrid, como los Capúz, de origen genovés, y Giacomo o Jacopo Bertessi, que residió en la Corte antes de establecerse en Valencia, donde realizó hacia 1700 el relieve de la Virgen del Rosario y los personajes bíblicos de la fachada y del interior respectivamente de la iglesia de San Juan del Mercado (Cfr. Martín González, op. cit., 1983, pp. 337 y ss.).

${ }^{28}$ Palomino de Castro y Velasco, op. cit., edic, 1947, pp. 1014-1015. Juan Agustín Ceán Bermúdez. Diccionario de los más ilustres profesores de las Bellas Artes en España. Tomo IV. Madrid, 1800, p. 163. Juan José Martín González. Escultura barroca en España, 1600-1750. Madrid, 1983, p. 275.

AEA, LXXVIII, 2005, 312, pp. 413 a 438 
El fragmentario conocimiento de la escultura madrileña y la escasez de obras conservadas de estos maestros no nos permite establecer comparaciones ${ }^{29}$ y dificulta la resolución del problema que plantea este Escudo de armas de Carlos II entre ángeles tenantes.

La acogida de la obra de las Calatravas bajo la tutela del patronato real permitiría en principio apuntar en la dirección de los escultores de cámara de la época de Carlos II, pero la sucesión en el cargo es inconexa: Juan Bautista Morelli (desde 1664), quizá Sebastián Herrera Barnuevo (1669-1671?), Pedro de Obregón (1672), José de Mora (desde 22 de noviembre de 1672), Enrique Cardón (desde17 de noviembre de 1687) y Luisa Roldán (desde 15 de octubre de 1692).

Casi todos ellos ofrecen más motivos para ser descartados que para ser considerados como posibles autores del adorno de la iglesia de las Calatravas. Pedro de Obregón (c. 1620- Madrid, 1672), pintor y escultor, declaraba conocer a Morelli cuando en 1670 fue llamado para informar en ciertos autos referentes a las cuentas presentadas por Andrés Smith, testamentario y tutor de los hijos del escultor, manifestando tener unos cincuenta años. Según Agulló y Pérez Sánchez, Obregón fue nombrado escultor de la Casa del Rey Carlos II en 1672, ocupando la plaza vacante en 1669 por fallecimiento de Morelli ${ }^{30}$. Pero detentó dicho honor por poco tiempo, pues José de Mora obtuvo su nombramiento como escultor del rey el 22 de noviembre de 1672 en la vacante de Obregón ${ }^{31}$, no pudiendo ser el escultor del adorno. José de Mora (Baza, 1624-Granada, 1724), que regresó a Granada en 1680, se había formado en Granada dentro del estilo de Alonso Cano, reafirmándolo en Madrid en contacto con Herrera Barnuevo, como lo demuestran las obras de este primer periodo ${ }^{32}$. Resulta curioso comprobar que su regreso a Granada fue inmediatamente posterior a las obras de la entrada de la reina María Luisa de Orleans, para las que no se debió pedir su participación, a pesar de su condición de escultor del rey. De Enrique o Hendick Cardón (muerto en Madrid, 1700) conocemos su nombramiento como escultor del rey en 1688, aunque con efectos desde el año anterior ${ }^{33}$, y su trabajo de tasación de las esculturas de don José Rubín, caballero de Santiago, realizado el 19 de diciembre de $1693^{34}$. Participó en las obras de escultura de la entrada de la reina María Luisa de Orleans en Madrid, en concreto en la del Arco de los Italianos contratada por Pedro Alonso de los Ríos.

En este mismo contexto de escultores del rey, autores de obras desconocidas o no conservadas, merece citarse que uno de los conjuntos escultóricos más importantes del reinado de Carlos II son los relieves de mármol y los bronces del retablo de la Sagrada Forma del monasterio de San Lorenzo del Escorial, deficientemente estudiado.

A modo de conclusión, el Escudo de armas de Carlos II entre ángeles tenantes de la iglesia de las Calatravas de Madrid es una obra que puede datarse entre 1678 y 1684 . En ella se

\footnotetext{
${ }^{29}$ Sobre la situación de la escultura en Madrid en el último tercio del siglo xviI, véase Martín González, op. cit., 1983, pp.225 y ss y 272 y ss.

${ }^{30}$ Ibidem. También Agulló y Pérez Sánchez, op. cit., 1976, p. 110. Aunque no existe rigor en la dotación de las plazas tras el fallecimiento de sus titulares, los tres años trascurridos entre la muerte de Morelli y el nombramiento de Obregón pueden explicarse si se atiende a que Sebastián Herrera Barnuevo no fallecería hasta 1671 y a que este escultor, pintor y arquitecto reunió en su persona varios títulos, como los de maestro mayor de Obras Reales y de la Villa de Madrid.

Sobre la identificación de este Pedro de Obregón con el pintor de igual nombre y sus dificultades, vid supra, nota 11.

31 J. J. Martín González, El escultor en Palacio. (Viaje a través de la escultura de los Austrias). Madrid, 1991, p. 221 y ss. y nota 1. Se sorprende Martín González del desconocimiento de las obras de Obregón como escultor. Algunas haría que le llevaran hasta el nombramiento, pero muy pocas como escultor del rey, pues el nombramiento de José de Mora en el mismo año de 1672 implica la muerte de Obregón.

${ }^{32}$ Martín González, op. cit., 1983, pp. 225 y ss.

${ }^{33}$ Para la fecha de su muerte véase Ceán Bermúdez, op. cit., tomo I, 1800, p. 239. Los documentos de su nombramiento en Martín González, op. cit., 1991, p. 225 y nota 3.

${ }^{34}$ Mercedes Agulló y Cobo. Documentos sobre escultores, entalladores y ensambladores de los siglos XVI al XVIII. Valladolid, 1978, p. 39.
}

$A E A$, LXXVIII, 2005, 312, pp. 413 a 438 
percibe con absoluta claridad una coincidencia con el canon estético de la escultura barroca que desarrollaron en Roma Gian Lorenzo Bernini y sus colaboradores, especialmente Antonio Raggi, en las décadas de 1660-1680. La presencia en Toledo y Madrid del escultor Pietro di Martino Veese, que quizá llegó a España en 1678 en el séquito del cardenal Portocarrero y participó en los trabajos de escultura de la puerta del Buen Retiro y de la Plaza del Palacio Real con motivo de la entrada de la reina María Luisa de Orleans (1679), permiten proponerle como posible autor del citado relieve en estuco.

ISMAEL GUTIÉRREZ PASTOR

Universidad Autónoma de Madrid

\section{UN CUADRO DE ALTAR DE TRASFONDO IDEOLÓGICO: «LA GENEALOGÍA DE LOS GUZMANES», DEL PINTOR BARROCO FRANCISCO JUANETE (1612).}

Para el año de 1612 los poderosos duques de Medina Sidonia, como señores naturales de Sanlúcar de Barrameda (Cádiz), ciudad que protegía la entrada a la barra del Guadalquivir y antecedía al puerto de Sevilla como cabecera de las flotas a Indias, tenían asumido el engrandecimiento de la misma, por ser sede de su Casa y poderío, con un programa urbanístico, arquitectónico y artístico de gran calado, del que son buen exponente las numerosísimas fundaciones religiosas ${ }^{1}$ que la convirtieron en una auténtica ciudad-convento barroca. De ahí su efectivo mecenazgo en el mundo de las artes, pues se necesitaban no sólo capacitados edificios para las comunidades de religiosos que allí vivían o recalaban temporalmente en tránsito para las Américas, sino de los indispensables ajuares litúrgicos y devocionales para sus iglesias y conventos, lo que favoreció la llegada al lugar de artistas y obras de centros primarios como la cercana Sevilla y, a la par, la creación de una pequeña corte de maestros albañiles, carpinteros y cañeros, ensambladores de retablos, escultores e imagineros, pintores, orfebres y lapidarios, que comían a mesa y mantel de la despensa ducal y que trabajaron afanosamente y por menor salario para la familia casi a tiempo completo ${ }^{2}$. Sin olvidar las obras civiles y urbanísticas que el municipio requería, las defensivas ${ }^{3}$, y las propias de su palacio, imagen y sím-

\footnotetext{
1 Véase: Cruz Isidoro, Fernando: El Santuario de Ntra. Sra. de la Caridad, de Sanlúcar de Barrameda. Estudio histórico-artístico. Córdoba, 1997. Del mismo autor: La Hermandad del Nazareno de Sanlúcar de Barrameda. Historia y Arte. Sanlúcar de Barrameda, 1998; El convento sanluqueño de Capuchinos. Arte e Historia de una fundación guzmana. Sanlúcar de Barrameda, 2002; «La Casa ducal de Medina Sidonia y el convento de Capuchinos de Sanlúcar de Barrameda: patronato y construcción», Laboratorio de Arte n. ${ }^{\circ} 13$. Sevilla, 2000, pp. 87-109.

${ }^{2}$ Sobre el mecenazgo artístico de los Medina Sidonia véase: Cruz Isidoro, Fernando: «Aproximación a la obra del arquitecto Asensio de Maeda». Archivo Hispalense n..$^{\circ}$ 237. Sevilla, 1995, pp. 107, 112. Del mismo autor: «Luis Sánchez y Jacques de Uparque, plateros de la Casa ducal de Medina Sidonia». Laboratorio de Arte n. ${ }^{\circ}$ 10. Sevilla, 1997, pp. 413-430. «Francisco Juanete, pintor de cámara de la Casa ducal de Medina Sidonia (1604-1638)». Laboratorio de Arte n. ${ }^{\circ} 11$. Sevilla, 1998, pp. 435-459. «Una nueva imagen iconográfica de la Sevilla de principios del xvir: como Cívitas Dei». Archivo Español de Arte $\mathrm{n}^{\circ}$ 290. Madrid, 2000, pp. 176-182. «Francisco de La Gándara Hermosa de Acevedo, un escultor de principios del XVII». Laboratorio de Arte n. $^{\circ}$ 14. Sevilla, 2001, pp. 27-49. "Vasco Pereira y la serie de seis retablos dominicos para la Casa ducal de Medina Sidonia». Laboratorio de Arte n. ${ }^{\circ}$ 15, Sevilla, 2002, pp. 357-364. «La Divina Pastora del Convento capuchino de Sanlúcar de Barrameda». Estudios Franciscanos. Publicación periódica de ciencias eclesiásticas de las provincias capuchinas ibéricas. Vol. $104 \mathrm{n}{ }^{\circ}$ 435. Barcelona, 2003, pp. 503-520. «Una nueva obra del escultor Diego Roldán Serrallonga». Revista Escuela de Imaginería. Año VII. Córdoba, 2000, pp. 32-37.

${ }^{3}$ Cruz Isidoro, Fernando: «Una defensa del Guadalquivir en su desembocadura: el castillo de San Salvador, en Bonanza». El emperador Carlos y su tiempo. Actas IX Jornadas Nacionales de Historia Militar. Sevilla, 2000, pp. 427-447.
} 